\title{
Stem-Cell Clinging by a Thread: AFM Measure of Polymer-Brush Lateral Deformation
}

Citation for published version (APA):

Gunnewiek, M. K., Ramakrishna, S. N., di Luca, A., Vancso, G. J., Moroni, L., \& Benetti, E. M. (2016). Stem-Cell Clinging by a Thread: AFM Measure of Polymer-Brush Lateral Deformation. Advanced Materials Interfaces, 3(3), [1500456]. https://doi.org/10.1002/admi.201500456

Document status and date:

Published: 05/02/2016

DOI:

10.1002/admi.201500456

Document Version:

Publisher's PDF, also known as Version of record

Document license:

Taverne

Please check the document version of this publication:

- A submitted manuscript is the version of the article upon submission and before peer-review. There can be important differences between the submitted version and the official published version of record.

People interested in the research are advised to contact the author for the final version of the publication, or visit the DOI to the publisher's website.

- The final author version and the galley proof are versions of the publication after peer review.

- The final published version features the final layout of the paper including the volume, issue and page numbers.

Link to publication

\footnotetext{
General rights rights.

- You may freely distribute the URL identifying the publication in the public portal. please follow below link for the End User Agreement:

www.umlib.nl/taverne-license

Take down policy

If you believe that this document breaches copyright please contact us at:

repository@maastrichtuniversity.nl

providing details and we will investigate your claim.
}

Copyright and moral rights for the publications made accessible in the public portal are retained by the authors and/or other copyright owners and it is a condition of accessing publications that users recognise and abide by the legal requirements associated with these

- Users may download and print one copy of any publication from the public portal for the purpose of private study or research.

- You may not further distribute the material or use it for any profit-making activity or commercial gain

If the publication is distributed under the terms of Article $25 \mathrm{fa}$ of the Dutch Copyright Act, indicated by the "Taverne" license above, 


\title{
Stem-Cell Clinging by a Thread: AFM Measure of Polymer-Brush Lateral Deformation
}

\author{
Michel Klein Gunnewiek, Shivaprakash N. Ramakrishna, Andrea di Luca, \\ G. Julius Vancso, Lorenzo Moroni, and Edmondo M. Benetti;
}

If the binding strength of adhesive cues to the extracellular matrix (ECM) and the mechanisms involved in cell adhesion are synergistically correlated via a "mechanical" feedback, engineering of cue presentation at the ECM by designer macromolecules can enable control over cell-matrix interaction. Here, polymer brushes supporting fibronectin (FN) and presenting different grafted-chain length to modulate cell interaction at ECM cell-binding sites are exploited. Application of friction force microscopy allows us to estimate the lateral deformability and friction of oligoethylene glycol-containing brushes. These parameters are demonstrated to regulate the adhesion of human mesenchymal stem cells (hMSCs), which adopt their morphology and form focal adhesions (FAs) responding to FN brush-tether characteristics. Across a brush-thickness gradient presenting uniform $\mathrm{FN}$ exposure, thin brushes stimulate cell spreading and the development of FAs. Conversely, thick and more laterally deformable polymer grafts induce a decrease in cell spreading and FA formation. A correlation between frictional forces experienced at the (macro)molecular scale and the behavior of stem cells has been found. This interaction can be clarified by exploring novel aspects of FFM, which demonstrates a powerful tool to dynamically probe the ECM environment and indirectly suggest a way to structure ECM in order to trigger specific cell responses.

\section{Introduction}

Macromolecular engineering of biomaterial interfaces by hydrophilic polymeric grafts organized in "brush" assemblies has been increasingly studied as a general strategy both to modulate surface functions and physical properties. ${ }^{[1]}$ This is assured by the morphology of a number of hydrophilic, densely chain end-grafted macromolecules which, in order to reduce their configurational entropy, stretch out at the interface, becoming solvated and forming an osmotic "barrier" against unspecific surface interactions. ${ }^{[2,3]}$ Application of similar antibiofouling brush substrates offers a way to hinder and/or regulate surface contamination by small biomolecules or large biological objects, such as bacteria and cells..$^{[4,5]}$ Simultaneously, the high surface density of functions on brush assemblies can be exploited for multiple bioconjugation, thus enabling the stimulation of specific biological events at the surface of the modified biomaterials. ${ }^{[6-9]}$ Precise choice of polymer composition and architecture (i.e., controlled branching ${ }^{[10]}$ or introduction of crosslinks ${ }^{[11]}$ additionally enables a wide modulation of the interfacial physical properties of the films, such as swelling, layer stiffness, or lubricity. ${ }^{[12]}$ All these features have attracted the attention of materials scientists who applied brush coatings not only to prevent the adsorption of proteins and microbes, but also to design cell-adhesive interfaces and subsequently study cellular response to different physical or biochemical stimuli. These last studies are not restricted to addressing cell adhesion and proliferation, but recently have also focused on dissecting the mechanisms of settlement and differentiation by stem cells. ${ }^{[7,13]}$

In all these applications, the preliminary investigation of the physico-chemical properties of polymer brush films used as a platform has been of paramount importance. This includes the characterization of the swelling properties of brushes by surface-sensitive techniques, and their mechanical and tribological properties, which are determined by polymer composition, molar mass (brush thickness), and brush grafting density. In order to study polymer-brush mechanical and tribological properties, atomic force microscopy (AFM)-based methods have been especially employed. AFM nanoindentation ${ }^{[14]}$ and friction force microscopy $(\mathrm{FFM})^{[15]}$ have allowed Young's modulus

DOI: 10.1002/admi.201500456 
(E) and coefficient of friction (COF) of polymer brushes to be estimated in aqueous and biologically relevant media. In particular, COF of several densely grafted, hydrophilic and charged polymer brushes showed extremely low values due to the very high osmotic pressure and the entrapment of water within the brush layers. ${ }^{[16-18]}$

Although several studies concentrated on the tribological properties of polymer brushes, on both the micrometer scale and across larger distances, ${ }^{[16,19-21]}$ a direct evaluation of the lateral deformability of grafted macromolecules and its dependency on brush parameters (such as grafted chain length) have received virtually no attention. This measurement could in principle be used to elucidate interfacial interactions between dynamic objects such as surface-interacting cells and brushfunctionalized substrates, and specific functions or proteins exposed at the brush interface. In the case of brush-adhesive protein cue conjugates, as an example, the estimate of brush lateral deformability could be associated with the interfacial availability of proteins when an adhered cell is spreading onto the brush support.

The relationship between the presentation of cell-adhesive cues, the physical and structural properties of synthetic extracellular matrices (ECMs) and the response of stem cells (including adhesion, spreading, migration, proliferation, and differentiation) has been the subject of several recent studies in the fields of biomaterials and regenerative medicine. ${ }^{[22-35]}$

The stiffness of elastic, hydrogel supports was particularly proposed as a key property to influence stem-cell fate, ${ }^{[31,35-39]}$ whereas stem cells from diverse sources were shown to adopt different morphologies depending on the mechanical properties of the substrate, spreading, forming stronger focal contacts and developing a more marked cytoskeleton network on stiffer supports. ${ }^{[31,36,40-43]}$ These differences in behavior eventually correlated with a tendency to differentiate toward a particular tissue type. ${ }^{[31,40,41,44]}$

Matrix-stiffness-related effects have been also interpreted as originating from the tethering strength of adhesive cues on the ECM and the consequent cell-traction generation, ${ }^{[40,45-47]}$ rather than directly being due to the mechanical properties of the supporting substrates. ${ }^{[48]}$ According to this view, strongly bound cell ligands on more rigid ECMs stimulate cell traction and intracellular mechanotransduction. This phenomenon is accompanied by the formation of mature and well-developed focal adhesions (FAs), ${ }^{[49]}$ depending on the applied cell adhesion force, ${ }^{[50,51]}$ and promote cell spreading and cytoskeleton development. ${ }^{[46,52]}$

The application of viscoelastic supports, more closely mimicking the natural ECM, provided additional insight in the relationship between substrate mechanics and stem-cell behavior. Cells on high-loss-modulus substrates were shown to compensate the dissipation of mechanical energy induced by cell dynamics generating active work and consequently increasing their spreading area. ${ }^{[53,54]}$ This was also correlated with the formation of small and transient FA complexes, characteristic of more motile and actively spreading cells. ${ }^{[53]}$

All these findings highlighted that active forces generated by cells correspond to passive forces counterbalanced by the ECM through an equilibrium that governs cell behavior and can ultimately trigger differentiation. Within this mechanism,
cue-integrin-FA adducts transduce forces directly to the cytoskeleton to an extent that is a function of the mechanical feedback experienced during cell contraction. ${ }^{[41,48]}$

Whether mechanotransduction is determined by the binding strength of adhesive cues or, primarily, by the intrinsic mechanical properties of the supporting ECM, ${ }^{[49]}$ what was unanimously recognized is that transduction of mechanical work determines ECM remodeling by cells and controls membrane and intracellular activities that direct differentiation. ${ }^{[47]}$

On 2D substrates, lateral forces and friction between cells and ECM interface were recently interpreted as being coresponsible for the signaling pathways during mechanotransduction, as cells are capable of reorganizing ligand presentation to an extent that is directly related to the dissipative frictional forces which originate at the ECM surface. ${ }^{[55-60]}$ Hence, interfaces featuring precisely tunable friction and allowing controlled tethering of cues could in principle actively control the mechanism of cell adhesion and, consequently, mechanotransduction.

In order to investigate the effects of cue-tether lateral deformability and frictional dissipation at the ECM interface on the mechanism of stem cell adhesion, we designed, fabricated and characterized FN-supporting poly(oligoethylene glycol)methacrylate (POEGMA) brushes featuring a continuous spatial gradient of grafted chain lengths. POEGMA brush-thickness gradients were initially synthesized by spatially controlled surfaceinitiated atom-transfer radical polymerization (SI-ATRP ${ }^{\text {[61-63] }}$ of oligo(ethylene glycol)methacrylates (OEGMA). ${ }^{[64]}$ The socreated brush gradient was subsequently covalently coupled to FN, finally yielding ECM platforms that exposed cell cues with different polymer-tether lengths to the substrate.

FFM was subsequently applied in order to evaluate the lateral deformability (brush lateral strain) of POEGMA-FN adducts under a colloidal probe sliding against the brush at rates and loads that are compatible with typical cell-spreading dynamics. At constant brush composition, grafting density, and solvent content, this parameter is demonstrated to be dependent on grafted-chain length, i.e., brush thickness.

This measurement was correlated with frictional properties, i.e., the frictional dissipation of POEGMA brushes along the gradient, quantified by analyzing friction-versus-load profiles. The results of FFM indicated that longer chains on thicker brushes could be laterally deformed to a larger extent when compared to shorter grafts on thinner brush assemblies. More deformable, thicker brushes also showed higher friction, indicating that the frictional dissipative character of POEGMA-FN adducts progressively increased with the length of the polymer tethers.

The adhesion of hMSCs at different positions along the brush gradient was subsequently tested. Cell spreading, cytoskeleton morphology, and formation of FAs all confirmed that changes in cell-attachment strength were occurring as a function of POEGMA brush thickness, and they correlated to the different deformability and frictional dissipation of the grafts along the gradient.

A height variation of high-aspect-ratio micropatterns as supports for cell settlement was already used to produce adhesive substrates that responded to cell traction forces as a function of the degree of pattern rigidity. ${ }^{[4]}$ In the present study a similar concept has been scaled down to the (macro)molecular level. 
The application of polymer brushes and the analytical tools employed here proved to be convenient and easily accessible strategies to enhance our understanding of stem cell attachment mechanisms.

\section{Results and Discussion}

\subsection{POEGMA-Brush Synthesis and Characterization}

POEGMA brushes were grafted from flat, spin-coated $(\approx 100 \mathrm{~nm})$ PCL films using SI-ATRP. Aminolysis of the PCL surface was used to produce free amino groups that can be used to couple the ATRP initiator functions ( $\alpha$-bromoisobutyryl bromide, BIBB) (Scheme 1a). Due to the "living" character of SIATRP, brush thickness could be well controlled by adjusting the polymerization time (Figure S1, Supporting Information). Thus different samples presenting increasing POEGMA brush thicknesses (keeping the grafting density constant) could be synthesized from initiator-modified PCL films by controlling the exposure time to the polymerization medium (Scheme 1b). In a typical fabrication process, a POEGMA-brush-thickness gradient was synthesized by vertically placing a $10 \mathrm{~mm} \times 20 \mathrm{~mm}$ initiator-functionalized PCL substrate inside an argon-purged vial, while OEGMA SI-ATRP solution was slowly added via a syringe pump-controlled injector (Scheme 1b). Following this procedure POEGMA brushes with a gradient thickness ranging from around 10 to $50-60 \mathrm{~nm}$ could be obtained on a single substrate (Scheme 1c). Every monomer segment presented 10-11 EG units, which allowed the polymer to swell when immersed in aqueous media, while the hydroxyl-terminating side-chain ends were exploited for bioconjugation. The swollen thickness of POEGMA brush gradients was measured by variable angle spectroscopic ellipsometry (VASE) in both ultrapure water and $\alpha$-MEM medium, which was subsequently used for cell culture. Within the range of brush thicknesses studied, the solvent content was found to be nearly constant along the gradient and varied from $50 \%$ to $60 \%$ in ultrapure water to $35 \%-40 \%$ in $\alpha$-MEM (Table S1, Supporting Information). From these measurements, we could estimate a constant POEGMA grafting density $(\sigma)$ of around 0.3 chains $\mathrm{nm}^{-2}$ applying the model proposed by Singh et al. for the same brush chemistry (using Equations (1) and (2) described in the Experimental Section). ${ }^{64]}$
Despite the fact that the calculated value of $\sigma$ certainly represented an overestimate, due to the bulkiness of each monomer unit and the particular polymer architecture of OEG-bearing polymethacrylates, the invariable swelling ratios recorded along POEGMA-brush gradients indicated a constant average $\sigma$, irrespective of the polymerization time applied across the sample. In order to confirm this, we incubated POEGMA-brush gradients in the presence of hMSCs over $4 \mathrm{~h}$ and subsequently monitored the unspecific cell adhesion across the gradient by immunofluorescence microscopy (Figure S2, Supporting Information). Densely grafted POEGMA brushes are known to hinder unspecific protein adsorption and cell adhesion, thus a constant $\sigma$ along the gradient would result in the near absence of adhered cells. ${ }^{[64-66]}$ As shown in Figure S2 (Supporting Information), nearly no cells adhered on POEGMA-brush gradient within the 10-60 $\mathrm{nm}$ thickness range, confirming the relatively high and uniform polymer grafting density along the gradient (more details regarding the effect of POEGMA grafting density on cell adhesion are reported in Table S2 and Figure S3 in the Supporting Information).

Having confirmed the efficient hindering of any nonspecific cell-brush interaction, POEGMA-brush gradients were modified by FN via $N, N^{\prime}$-disuccinimidyl carbonate (DSC)-mediated coupling between hydroxyl-terminating side oligomers of the monomer units and the proteins (see the Experimental Section for details) (Scheme 1a). Following overnight incubation in protein solutions of DSC-activated POEGMA, surface coverage of FN was quantitatively evaluated by X-ray photoelectron spectroscopy (XPS), VASE, and AFM (Figures S4,S5 and Table S3 in the Supporting Information). The protein surface concentration was found to be relatively low (included between 20 and $40 \mathrm{ng} \mathrm{cm}{ }^{-2}$ ) and uniform across the gradient, while an invariable surface exposure of the proteins was found at the interface of brushes presenting different thicknesses (a detailed description of FN loading on gradient POEGMA-brush films is reported in the Supporting Information).

\subsection{AFM Analysis of POEGMA Brush-Thickness Gradients}

In order to investigate the nanomechanical properties of POEGMA brushes presenting a thickness gradient, colloidal-probe AFM indentation (CP-AFM) was performed at
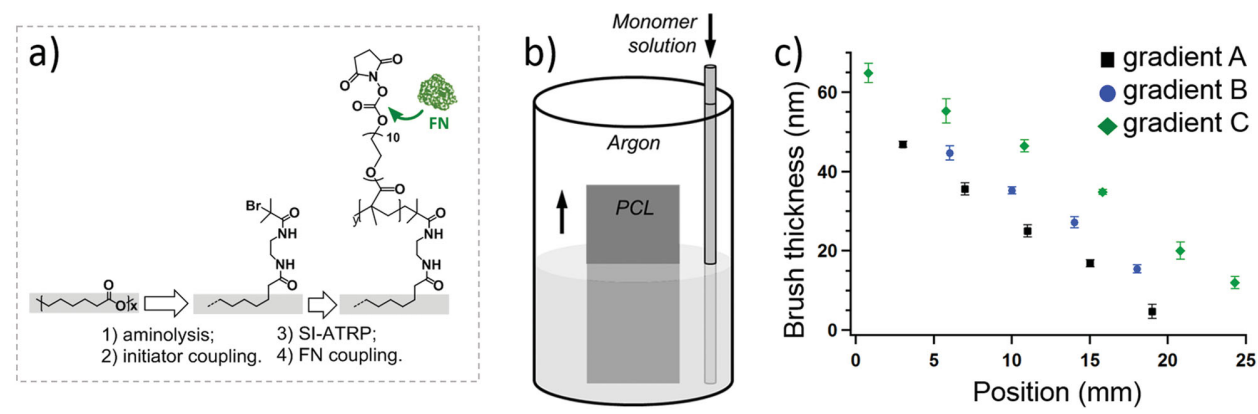

Scheme 1. a) Modification of PCL surfaces by (1) aminolysis and (2) ATRP initiator coupling, followed by fabrication of PCL-grafted POEGMA brushes by (3) SI-ATRP and final coupling of FN ligands by conjugation on succinimidyl carbonate derivatives of (4) OEG side chains. b) Schematic depicting the fabrication of POEGMA brushes presenting a gradient in thickness across a single substrate. c) POEGMA brush thickness as a function of position along three different fabricated gradients. These are indicated as "A," "B," and "C." 


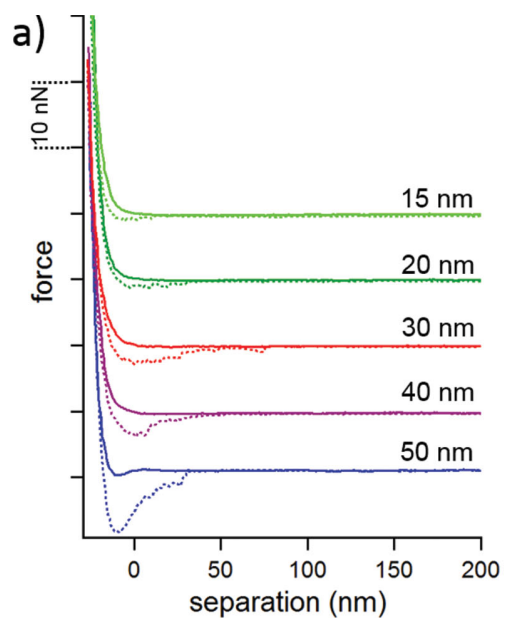

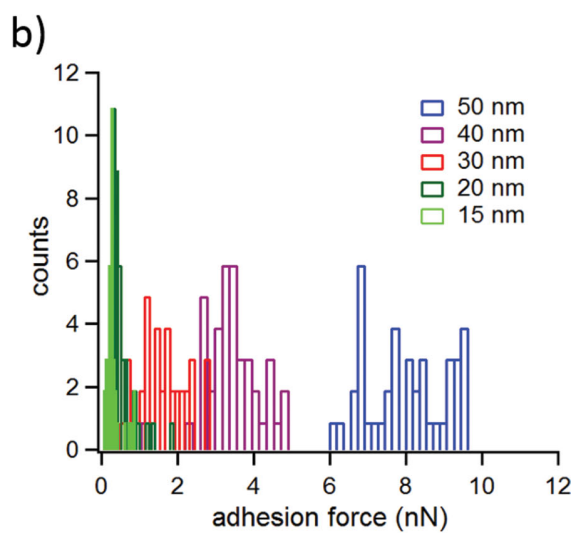

Figure 1. a) FS curves recorded along POEGMA brush thickness gradient for 15 (13 $\pm 3 \mathrm{~nm}$, light green traces), 20 (21 $\pm 2 \mathrm{~nm}$, dark green traces), 30 (29 $\pm 4 \mathrm{~nm}$, red traces), 40 (41 \pm $2 \mathrm{~nm}$, violet traces), and $50 \mathrm{~nm}(48 \pm 4 \mathrm{~nm}$, blue traces) thick brushes. The approaching curves are indicated as continuous traces, the retracting ones as dashed traces. FS curves were recorded using a silica sphere of $16 \mu \mathrm{m}$ diameter glued on a tip-less cantilever with a spring constant $k=1.63 \mathrm{~N} \mathrm{~m}^{-2}$. On each sampling position along the POEGMA gradient, the average brush thickness was evaluated prior CP-AFM by measuring with a sharp tip the step height between the polymer film and a neighboring area of the sample where the film was mechanically removed by plastic tweezers (measurement of the scratch). In (b), the distribution of the measured adhesion force values is reported for the different POEGMA brush thicknesses tested. values across the brush thickness gradient (Figure S6, Supporting Information).

The lateral deformability of the POEGMA brushes and the frictional properties as a function of tethered chain length were subsequently measured by FFM. We recently demonstrated that friction loops of hydrated brushes show "tilted" profiles between scanning-direction reversal and steady sliding. ${ }^{[69]}$ The tilted section of the loops originates from the lateral deformation of hydrated, surface-tethered chains when they are subjected to a sliding probe under load. The degree of tilt depends on the brush swelling ratio, the chemical structure of the graft, and the polymer chain length. In the present study, friction loops were recorded in $\alpha$-MEM medium by using a silica colloid of $16 \mu \mathrm{m}$ of diameter, keeping an applied normal load within 50-150 $\mathrm{nN}$ and laterally sliding the probe at $50 \mathrm{~nm} \mathrm{sec}{ }^{-1}$. ${ }^{[70]}$ Within this range of applied loads and scanning rates, we could generate lateral forces that fit well the typical traction forces exerted by stem cells and their spreading rates. ${ }^{[45,49]}$

In Figure 2a, a representative friction loop recorded on a $50 \mathrm{~nm}$ thick POEGMA brush different positions along the substrates immersed in $\alpha$-MEM medium. The obtained force-versus-separation (FS) curves recorded on 15 (13 $\pm 3 \mathrm{~nm}), 20$ (21 $\pm 2 \mathrm{~nm}), 30$ (29 $\pm 4 \mathrm{~nm})$, $40(41 \pm 2 \mathrm{~nm})$, and $50 \mathrm{~nm}(48 \pm 4 \mathrm{~nm})$-thick brushes are reported in Figure 1a, highlighting both approaching (continuous traces) and retracting profiles (dashed traces). For all the brush thicknesses studied within the thickness range 40-15 nm, nearly identical approaching curves were observed indicating a similar stiffness of the swollen POEGMA brushes across the gradient. The same normal stiffness of POEGMA brushes presenting different dry thicknesses was in agreement with the already observed swelling character of the films along the thickness gradient, which indicated constant values of solvent content and $\sigma$. In the case of $50 \mathrm{~nm}$ thick brushes, a different profile of the approaching curves was observed at contact point, with a "jump-in" followed by an increasing slope of the force curve which, at negative separation depths (penetration within the brush layer), followed a similar steepening as compared to the other brush thicknesses tested. The different behavior of thicker brush layers in the approaching FS profiles could be clarified by considering the relatively higher adhesion force recorded on thicker POEGMA brushes compared to thinner analogues. ${ }^{[14,67]}$ As evidenced by comparing the retracting portions of FS curves, a progressive increase of adhesion was recorded with increasing brush thickness (Figure 1b). This could be explained considering the attractive forces between the silica colloid used as a probe and the POEGMA grafts, which increased with the tethered polymer length. ${ }^{68]}$

Although within the range of thicknesses studied (15-50 nm of dry thickness, $30-80 \mathrm{~nm}$ of swollen thickness), the effect of the underlying substrate cannot be ruled out, an attempt to estimate the brush stiffness using Hertz model and considering less than $10 \mathrm{~nm}$ of indentation showed very similar $\mathrm{E}$ is reported, highlighting the lateral scanning direction with an arrow on each trace. In the graph, the lateral force generated between the surface and the sliding probe is plotted against the scanning distance. The corresponding lateral force-vs-time plot recorded during the loop and a schematic depicting the behavior of POEGMA brushes subjected to lateral sliding of a colloidal probe are reported in Figure 2b,c. The static friction at the normally compressed POEGMA brush (position "1" in Figure $2 \mathrm{~b}, \mathrm{c}$ ), coupled with the compliance of the hydrated layer, caused an initial tilting of the friction loop (section "2", corresponding to a scanning distance $X_{\mathrm{d}}$ ). This tilt originated from the deformation of the compressed grafts which are laterally bent and stretched by the sliding probe. ${ }^{[71]}$ Steady sliding could be attained just as the shear force exerted by the probe exceeded the spring force of the deformed brush ${ }^{\text {[2] }}$ (point $\mathrm{S}$ followed by section " 3 " corresponding to a scanning distance $X_{\mathrm{s}}$ ). After scanning-direction reversal (position " 4 "), the compressed brush is laterally deformed in the opposite direction (section "5") until sliding finally occurred ( $\mathrm{S}^{\prime}$, followed by section "6").

Varying the scanning distance at a fixed applied load and at constant brush thickness provided more information about the behavior of sheared POEGMA brushes. As reported in Figure S7 (Supporting Information), at relatively short scanning distances, steady sliding is not attained and the deformation of the grafted polymer dominates colloidal probe-brush interaction. At scanning distances larger than $X_{\mathrm{d}}$, sliding on the brush surface occurs, whereas the morphology of the tilted portion of the friction loop does not show any variation.

In Figure 3a, single traces from friction loops recorded applying $150 \mathrm{nN}$ of normal load at $50 \mathrm{~nm} \mathrm{~s}^{-1}$ of scanning rate on POEGMA brushes presenting different thicknesses across the gradient are reported. In order to ease the comparison among the different curves, the recorded lateral force traces 

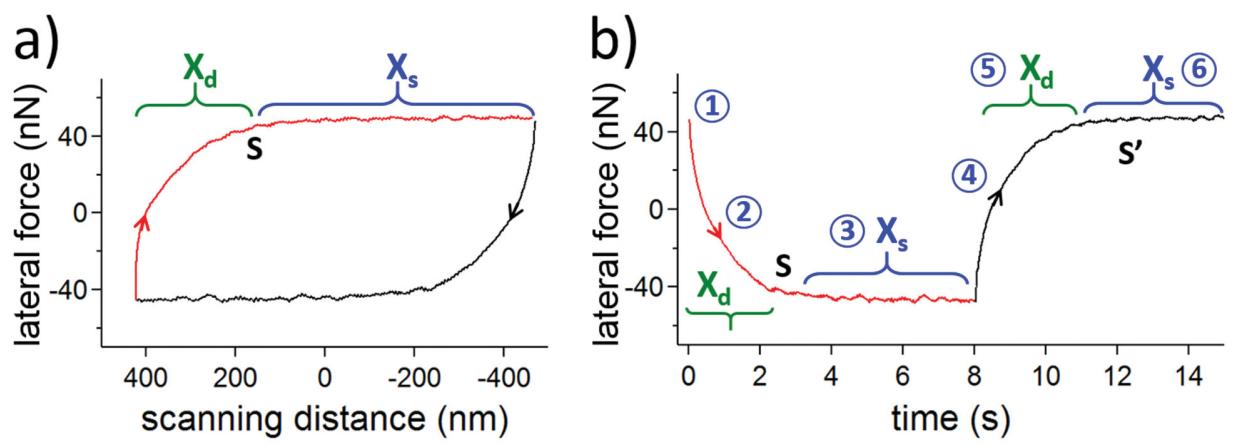

c) (1)
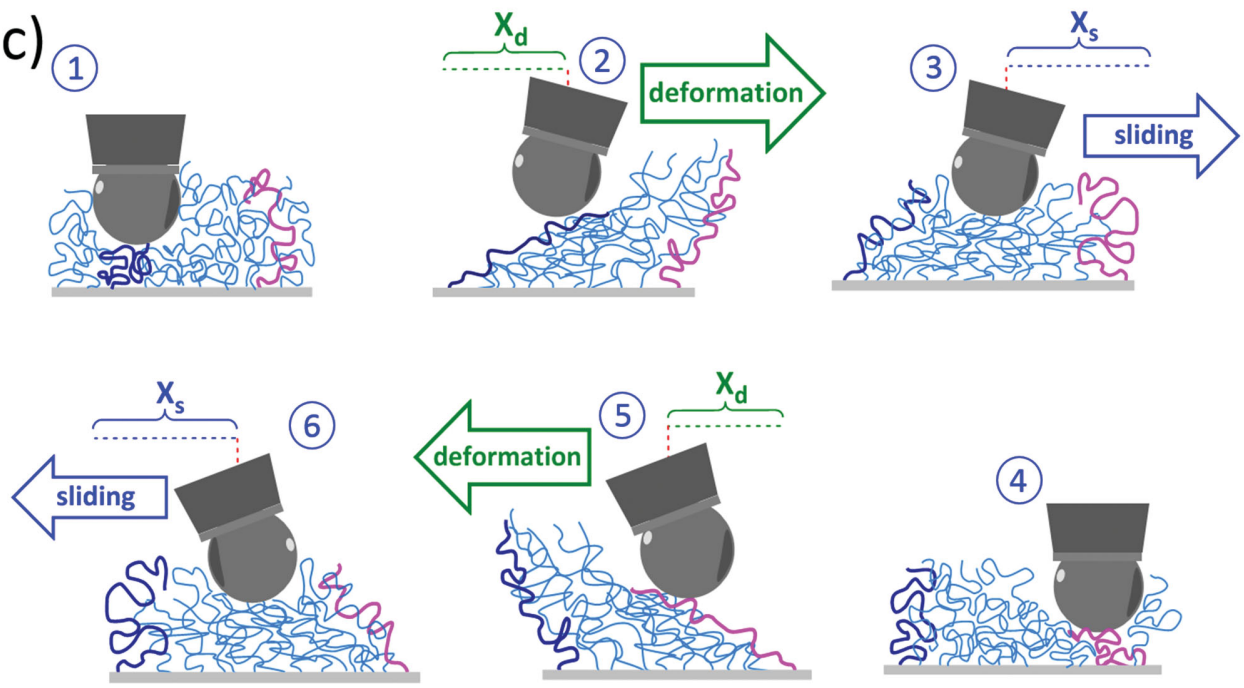

Figure 2. The measured lateral twist in the cantilever-vs-scanning distance plots from the AFM is referred as "friction loop," which is a measurement of the lateral force recorded between the cantilever and the surface. In (a), a representative friction loop obtained by FFM on POEGMA brush is displayed. $X_{\mathrm{b}}$ and $X_{\mathrm{s}}$ indicate the scanning distances corresponding to the laterally deformed brush and the steady sliding section of the loop, respectively; point $S$ indicates the transition between these two regimes; scanning direction is indicated by an arrow on both trace and retrace profiles. b) Lateral forcevs-time recorded during FFM on the same POEGMA brush studied in (a). The schematics in (c) depict brush-probe interaction during a friction loop. Two representative grafted chains are indicated in dark blue and pink color in order to highlight the lateral movement of the colloidal probe during the loop. The numbers on each schematic refer to the corresponding portion of the loop reported in (b). "1" the colloidal probe compresses POEGMA brushes; "2" initial lateral scanning induces bending and stretching of the grafted chains until sliding occurs in " 3 "; after scanning direction reversal, highlighted in "4," POEGMA brushes are laterally deformed in the opposite direction with respect to "2," until a final steady sliding is reached in "6" and closes the loop.
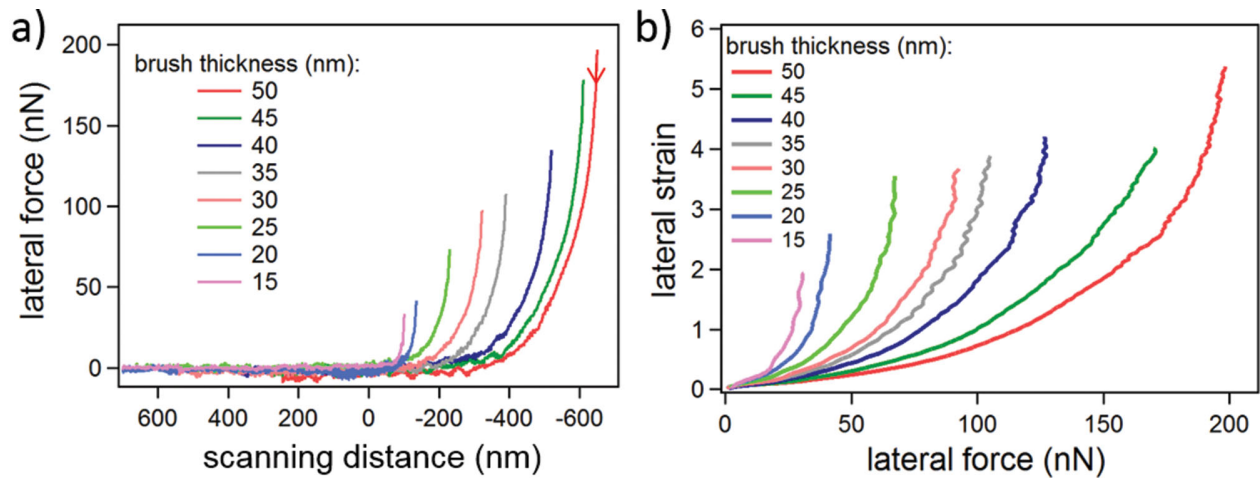

Figure 3. a) Single-traces from friction loops recorded at different positions along the POEGMA brush gradient; the brush thicknesses reported for each colored trace corresponds to the average thickness values measured by ellipsometry on the areas analyzed by LFM along the gradient: $50 \pm 5 \mathrm{~nm}$ ( $50 \mathrm{~nm}$, indicated for the red colored trace), $43 \pm 4 \mathrm{~nm}$ (45 nm, dark red), $40 \pm 4 \mathrm{~nm}$ (40 nm, dark blue), $36 \pm 3 \mathrm{~nm}(35 \mathrm{~nm}$, gray), $32 \pm 3 \mathrm{~nm}(30 \mathrm{~nm}$, pink), $27 \pm 2 \mathrm{~nm}$ ( $25 \mathrm{~nm}$, light green), $19 \pm 3 \mathrm{~nm}$ ( $20 \mathrm{~nm}$, light blue), $13 \pm 2 \mathrm{~nm}$ (15 nm, violet). b) Normalization of the tilted section of each loop ( $\left.X_{d}\right)$ by the equilibrium swollen thickness of the corresponding brush in $\alpha$-MEM yields brush lateral strain-versus-lateral force. Lateral strain-versus-lateral force profiles for the different POEGMA brush thicknesses studied are reported in (b) with each colored trace corresponding to the different brush thicknesses across the gradient already indicated in (a). 

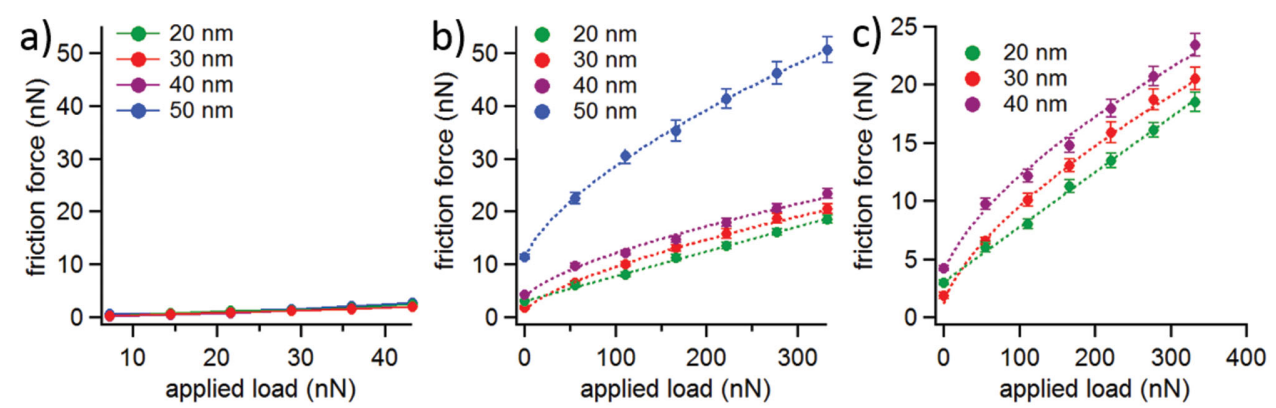

Figure 4. Friction-vs-load (FL) data recorded on POEGMA brushes presenting different thickness across a brush gradient. In (a), FL data were recorded in the load range included between 5 and $45 \mathrm{nN}$ using a $16 \mu \mathrm{m}$ diameter colloidal probe glued on a cantilever with $k=1.63 \mathrm{~N} \mathrm{~m}{ }^{-1}$. In (b), FL data were recorded between 0 and $350 \mathrm{nN}$, using a $16 \mu \mathrm{m}$ diameter colloidal probe glued on a cantilever with $k=3.39 \mathrm{~N} \mathrm{~m}^{-1}$. In (c), a zoomed-in on the FL data for 40, 30, and $20 \mathrm{~nm}$ thick brushes is reported. The dashed traces in (b) and (c) are fittings of the FL data with the generalized transition equation (GTE) as proposed by Carpick et al. ${ }^{[76]}$ The modeling of FL data and the application of the GTE equation are explained in detail in the Supporting Information.

were all set to 0 , in the position where steady sliding was attained along each trace. The increment of POEGMA brush thickness, and thus the concomitant increase in tethered-chain length, is reflected in an increase in the tilted-loop section before the occurrence of steady sliding.

Normalization of $X_{d}$, i.e., the scanning distance included between scanning direction reversal (starting of the tilted portion of the loop) and the point where sliding is reached ( $\mathrm{S}$ in Figure 1a) by the equilibrium swollen thickness of the corresponding POEGMA brush in $\alpha$-MEM, resulted in the brush lateral deformation (or brush lateral strain) as a function of the recorded lateral force. When this measurement was plotted for the different positions tested along the fabricated gradient, the increasing lateral strain of POEGMA brush with the increasing brush thickness (tethered-polymer length) is clearly demonstrated (Figure 3b).

As initially predicted by Rabin and Alexander, ${ }^{[72]}$ and later on confirmed by several theoretical and simulation studies, ${ }^{[71,73-75]}$ polymer brushes under strong shear forces can be laterally deformed well beyond their unperturbed, equilibrium extensions. This originates from the coiling of grafted polymer chains, which also within a "dense" brush do not extend further than $10 \%$ of their fully stretched length. For these reasons the estimated strain exceeded the equilibrium "length" for all the brush thicknesses studied (lateral strain $>1$ ), while longer chains can be laterally displaced to a larger extent compared to shorter ones and for a given applied shear stress. ${ }^{[71]}$ Hence, thicker polymeric grafts yielded higher lateral strain compared to thinner ones.

Interestingly, the brush lateral deformation measured in this way did not show a dependence on the scanning rate within the $20-400 \mathrm{~nm} \mathrm{~s}^{-1}$ range, as reported in Figure S8a (Supporting Information). Additionally, variation of the applied normal load from 50 to $200 \mathrm{nN}$ resulted in a slight increment of the overall deformation, for a given brush thickness. This was accompanied by a progressive increase of the measured lateral force, indicating that the more the brush is stretched, the higher is the measured friction (dissipation) during the deformation process (Figure S8b, Supporting Information).

In order to investigate how the frictional properties of POEGMA brushes vary with thickness and thus with the different deformability of the brushes, we subsequently recorded friction-vs-load (FL) data at four different positions across the gradient, on $53 \pm 3 \mathrm{~nm}, 41 \pm 2 \mathrm{~nm}, 27 \pm 2 \mathrm{~nm}$, and $18 \pm 3 \mathrm{~nm}$ thick POEGMA brushes (these will be indicated as 50, 40, 30, and $20 \mathrm{~nm}$ thick brushes, respectively).

Friction force values on the FL plots displayed in Figure 4 were obtained by averaging the measured lateral forces on trace and retrace from friction loops recorded under different applied normal loads.

It is noteworthy that at relatively low applied loads $(5-45 \mathrm{nN})$, no differences in frictional properties were observed along the POEGMA brush gradient (Figure 4a), whereas recording FL profiles at cell relevant forces $(50-300 \mathrm{nN})$ differences in behavior emerged upon incrementing the brush thickness (Figure 4b).

Generally, higher friction was recorded on the thicker side of the gradient, indicating that the increase in lateral deformability was associated to an increment of the frictional dissipation by POEGMA brushes. In addition, friction showed a sublinear dependence with applied load for thicker brushes, while for thinner ones a nearly linear trend for the FL data was observed. The transition of FL from linear to sublinear profiles could be explained by considering the contribution of adhesion for thicker POEGMA brushes (Figure 1) and the higher deformability of longer grafts compared to shorter analogues. The influence of deformability on the frictional behavior of POEGMA brushes presenting different thickness could be confirmed by applying continuum-contact-mechanics models to the recorded FL profiles. As reported in detail in the Supporting Information, the FL data for $50 \mathrm{~nm}$ thick brushes could be described by the Johnson-Kendall-Roberts (JKR) ${ }^{[77]}$ model, which is applicable for highly deformable materials. In contrast, a transition toward the Derjaguin-Müller-Toporov (DMT) ${ }^{[78]}$ model was found for the intermediate POEGMA thicknesses of 40 and $30 \mathrm{~nm}$, which are more resistant to deformation. Finally, the thinnest, $20 \mathrm{~nm}$ thick POEGMA brushes tested, followed Amontons' law ${ }^{[79]}$ with a linear FL profile and low friction coefficient (low dissipation).

The analysis of FL data thus confirmed the recorded brush lateral deformation from the friction loops measured along POEGMA brush gradients. Thicker brushes showed higher lateral deformability and their frictional properties could be described assuming a JKR model. Conversely, moving toward areas of the gradient presenting thinner grafts, a transition to DMT could be observed, highlighting how a decrease in 
tethered-chain length translated into smaller lateral strains and less deformable polymer layers.

In summary, the fabricated POEGMA brush gradients showed a constant solvent content when immersed in culture medium, indicating a constant grafting density across the gradient. This translated in an invariable biopassive character of POEGMA brushes in the thickness range $15-60 \mathrm{~nm}$. Once functionalized with $\mathrm{FN}$, the interfacial protein coverage showed a uniform distribution, as proved by AFM (Figure S5, Supporting Information), and a relatively low overall surface concentration when protein loading was tested by XPS and ellipsometry (Figure S4 and Table S3, Supporting Information).

FFM provided a measure of the lateral deformability of POEGMA brushes presenting different thickness across the gradient and allowed evaluating their frictional characteristics through the analysis of FL data. These measurements indicated that longer, more laterally deformable grafts featured higher frictional dissipation compared to thinner ones, and that these properties progressively varied along the brush gradient.

\section{3. hMSC Attachment on POEGMA-FN Gradients}

In order to test the adhesion of hMSCs on POEGMA-FN brushes of different thicknesses, the gradient samples were incubated in cell culture for $4 \mathrm{~h}$ and subsequently analyzed by optical and immunofluorescence microscopies (see Experimental Section for details). Figure 5 shows the images from hMSCs adhering at different positions on gradient POEGMA-FN brushes and the same cells on FN-functionalized PCL control surfaces.

Despite the number of attached hMSCs was significantly increased for $20 \mathrm{~nm}$ and $40 \mathrm{~nm}$ thick brushes (Figure 5d; Figures S10 and S11 in the Supporting Information), both fluorescence and optical imaging analysis (Figure 5) indicated that the spreading of hMSCs gradually and significantly decreased with increasing POEGMA brush thickness (Figure 5c). The reduction of hMSCs projected areas along the POEGMA brush gradient could not be due to a variation of FN concentration, given the nearly constant interfacial coverage of the protein across the samples. In addition, POEGMA brushes showed invariable swelling properties, grafting density, and compressive modulus. Hence, hMSCs necessarily responded to the modulation of the deformability by FN-POEGMA adducts (which also governs the frictional properties), generated by a gradual variation of graftedchain length across the gradient. In agreement with this hypothesis, a direct relationship between hMSCs area and POEGMA brush lateral deformability (expressed as maximum lateral strain) was found across the gradient platform (Figure 6).

Recent studies correlated cell spreading and cytoskeleton development to the dissipative character of ECM-cues a)

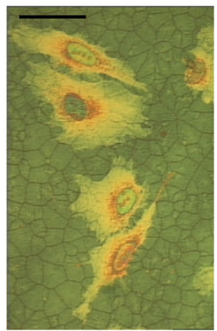

b)

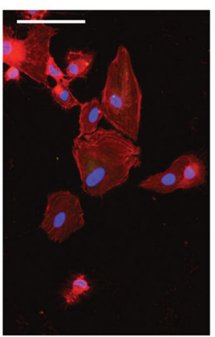

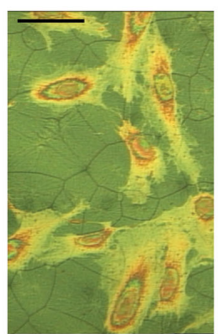
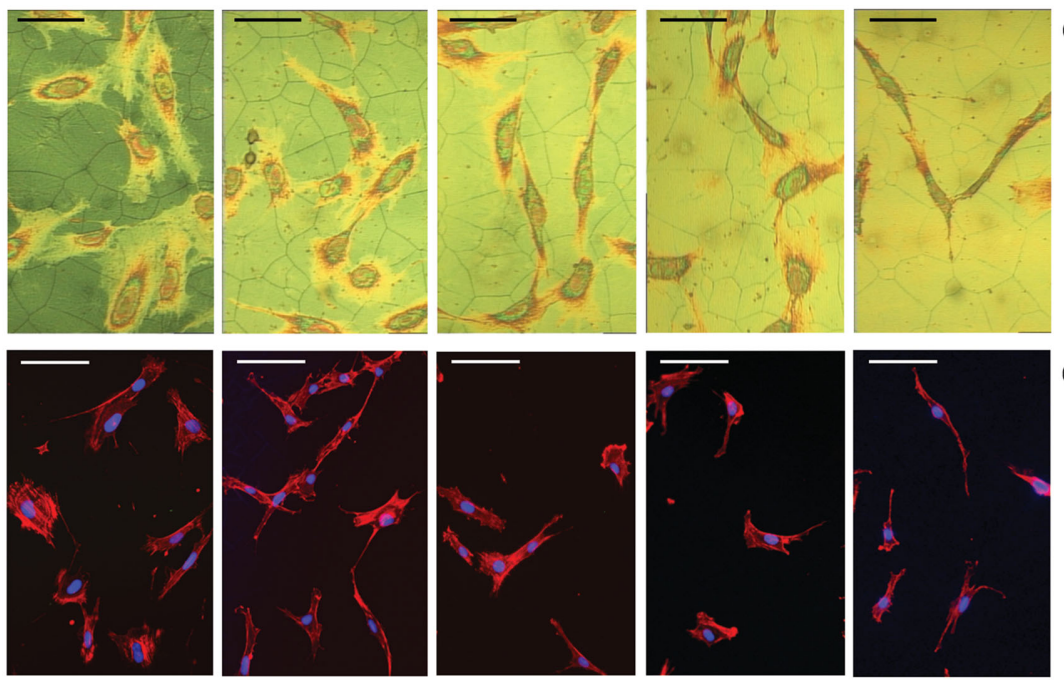

c)

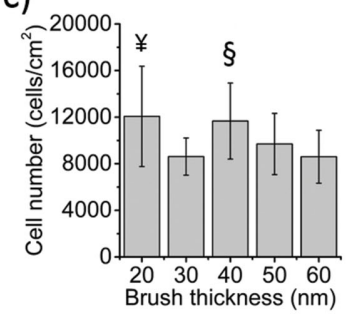

d)

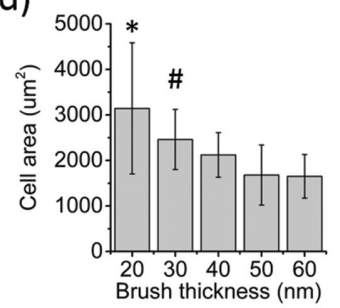

Figure 5. Adhesion of hMSCs on POEGMA-FN gradient brushes. a) Optical and b) immunofluorescence images showing hMSCs adhered at different positions along a POEGMA-FN brush gradient. In (b), the cytoskeletons were stained by rhodamine phalloidin (red) and the cell nuclei by DAPI (blue). From left to right: FN-functionalized bare PCL control, $13 \pm 2,19 \pm 3,32 \pm 3,40 \pm 4$ and $50 \pm 3 \mathrm{~nm}$ thick, FN-functionalized POEGMA brush. The black color scale bars in (a) correspond to $50 \mu \mathrm{m}$, the white color scale bars in (b) correspond to $100 \mu \mathrm{m}$. In (c), the average cell number measured on different positions along the gradient is reported; the value for "20 nm" corresponds to the areas on the gradient included between $19 \pm 3 \mathrm{~nm}$ and $27 \pm 2 \mathrm{~nm}$, "30 nm" between $27 \pm 2 \mathrm{~nm}$ and $32 \pm 3 \mathrm{~nm}$, " $40 \mathrm{~nm}$ " between $36 \pm 3 \mathrm{~nm}$ and $40 \pm 4 \mathrm{~nm}$, " $50 \mathrm{~nm}$ " between $43 \pm 4 \mathrm{~nm}$ and $50 \pm 5 \mathrm{~nm}$, " $60 \mathrm{~nm}$ " between $50 \pm 5 \mathrm{~nm}$ and the edge of the gradient; $¥$ indicates a statistically significant difference between the cell number on $20 \mathrm{~nm}$ thick brushes and cell numbers measured on brushes with a thickness of 30,50 , and $60 \mathrm{~nm}(\mathrm{p}<0.05)$; $\int$ indicates a statistically significant difference between the cell number on $40 \mathrm{~nm}$ thick brushes and cell numbers measured on 30 and $60 \mathrm{~nm}$ thick brushes $(p<0.05)$. Within the same areas, the average cell projected areas was measured and reported in (d); * indicates a statistically significant difference between the cell area measured on $20 \mathrm{~nm}$ thick brushes and cell areas measured on 40,50 , and $60 \mathrm{~nm}$ thick brushes $(p<0.05)$; \# indicates a statistically significant difference between the cell area measured on $30 \mathrm{~nm}$ thick brushes and cell areas measured on 50 and $60 \mathrm{~nm}$ thick brushes $(p<0.05)$. The POEGMA brush thickness corresponding to each image was recorded by AFM step-height analysis, imaging the cross-section between POEGMA brush-functionalized PCL and the underlying silicon oxide substrate exposed by mechanically removing the organic film with plastic tweezers ("scratched" film). PCL semicrystalline structures are visible in the OM images reported in (a); as previously demonstrated by us, ${ }^{[62]}$ functionalization by POEGMA brushes hindered any topographical effect on cell adhesion. 


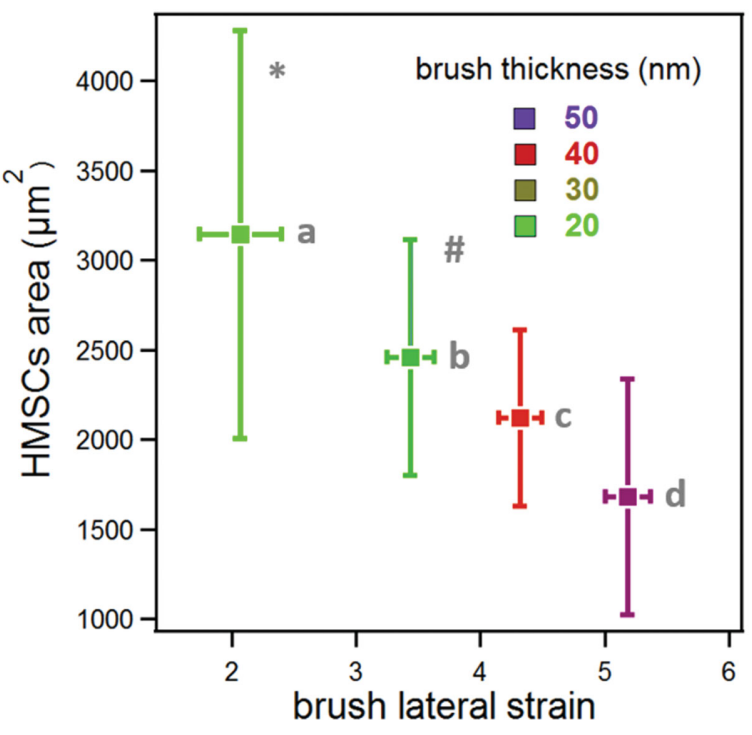

Figure 6. hMSCs projected area measured at different positions along POEGMA-FN brush gradient as a function of brush lateral strain. POEGMA brush thickness values are indicated by differently colored markers; * indicates a statistically significant difference between the cell area on $20 \mathrm{~nm}$ thick brushes and cell areas recorded on brushes with a thickness of 40 and $50(p<0.05)$; \# indicates a statistically significant difference between the cell area measured on $30 \mathrm{~nm}$ thick brushes and cell areas recorded on $50 \mathrm{~nm}$ thick brushes $(p<0.05)$; a, b, c, and d indicate statistically significant differences among the lateral strains by brushes presenting different thickness $(p<0.05)$.

adducts. ${ }^{[40,41]}$ In agreement with this view, the feedback mechanism that is initiated by traction forces of adhering cells determines the strength of cell attachment and the extent of spreading. ${ }^{[41]}$ On POEGMA brush gradients, the mechanical response of the brush-FN adducts correlates with tetheredchain length. As described in Section 2.2, this parameter determined the lateral deformability and consequently the frictional properties measured on the brushes. On less laterally deformable POEGMA brushes hMSCs spread more, compared to their behavior on thicker and more laterally deformable POEGMA-FN grafts, where cells showed reduced spreading.

Since different strengths of cell adhesion are usually correlated with the degree of formation of FA complexes, ${ }^{[48,50,51,80,81]}$ we specifically investigated the formation of FAs by hMSCs adhered across the brush gradient. We focused on cells on three main areas along the gradient corresponding to the "thin" (10-20 nm POEGMA thickness), the "medium" (30-40 $\mathrm{nm})$, and the "thick" brush regions (50-60 nm) (Figure 7a-c; Figure S12 in the Supporting Information). On thinner POEGMA-FN films, the formation of FAs was delocalized over the whole cell membrane (Figure 7a). With increasing brush thickness, FA complexes around the cell nuclei progressively disappeared while clear complexes were increasingly concentrated at the periphery of the membrane (Figure 7b,c). Besides the concentration of FAs, their morphologies also showed a marked dependency on brush length. In the fluorescence images reported in Figure $7 \mathrm{a}-\mathrm{c}$, it could be observed that FAs showed larger and more elongated morphologies in cases where hMSCs adhered to thinner, 10-20 nm thick POEGMA brushes. This observation was also confirmed by measuring and comparing the average FA area and aspect ratio for hMSCs adhered on the three different regions along the gradient (Figure $7 \mathrm{~d}, \mathrm{e}$ ). The average values of both these parameters gradually decreased with increasing a)

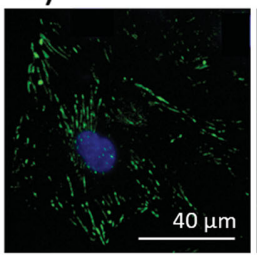

b)
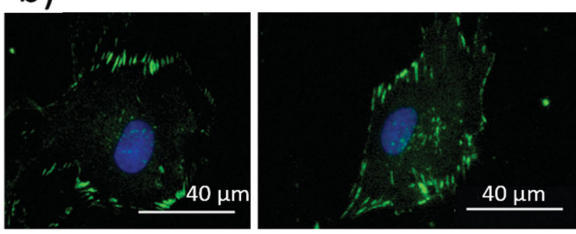

c)
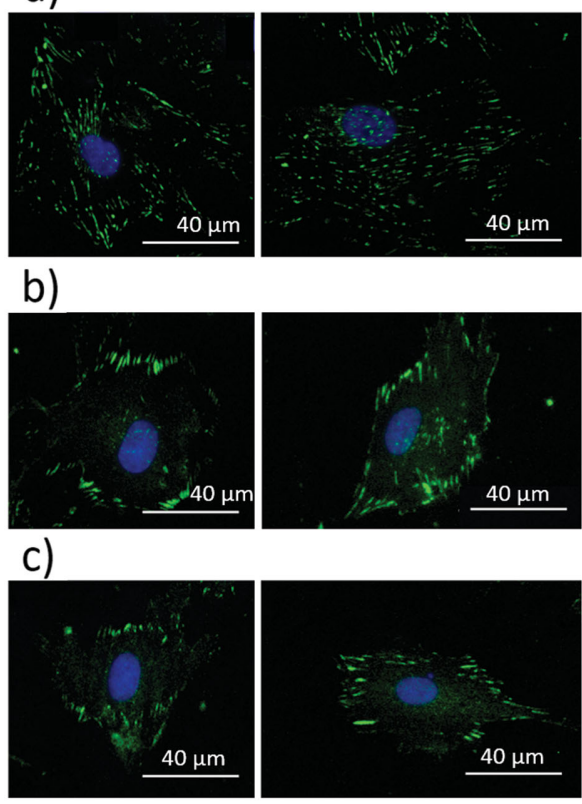
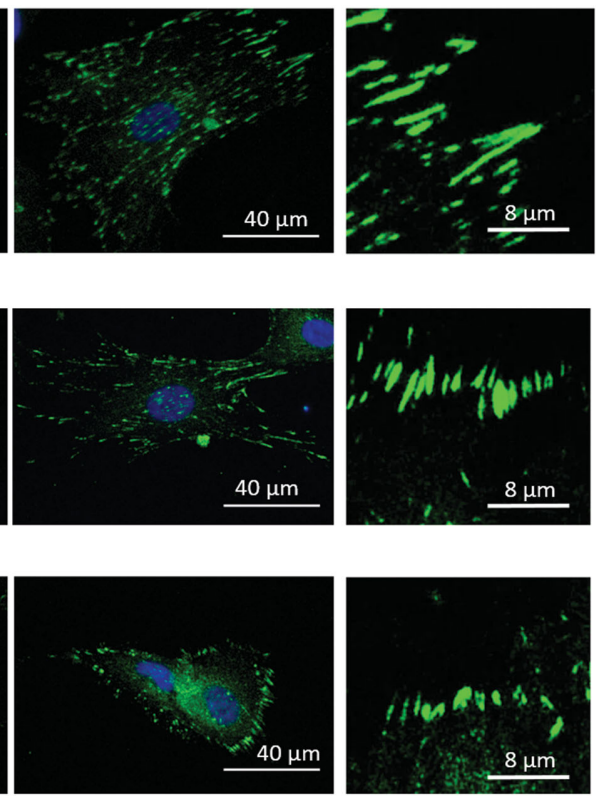
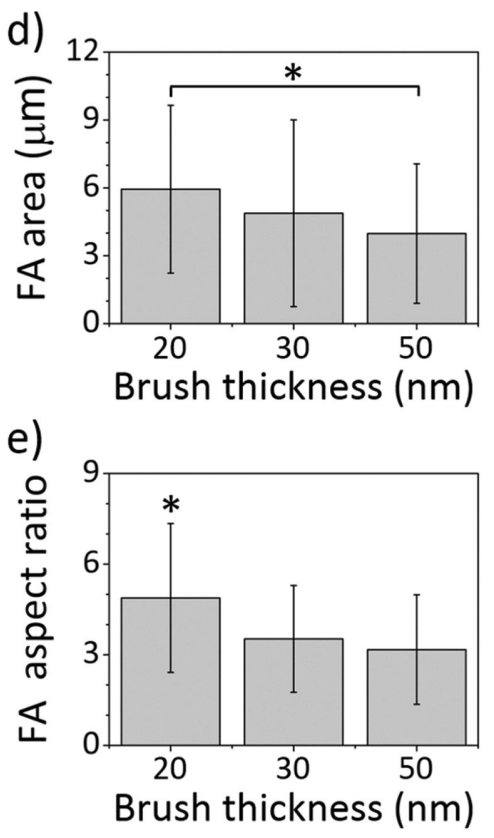

Figure 7. Immunofluorescence images showing the vinculin-associated FA complexes for hMSCs attached on a) $10-20$ nm, b) 30-40 nm, and c) 50-60 nm thick POEGMA brushes functionalized with FN. In (a)-(c), FAs were stained by FITC (green) and the cell nuclei by DAPI (blue). d) Average FA area and e) average FA aspect ratio. * denotes statistical significant differences between the assigned and the nonassigned topographies $(p<0.05)$. 
brush length, indicating how bigger and more oriented FA complexes were formed on the thinner regions of the POEGMA brush gradient. The observed changes in FA distribution and morphology could be interpreted in terms of cue mobility and cell-binding strength on POEGMA-FN platforms presenting different brush thicknesses. Thinner POEGMA-FN presenting limited lateral deformability induced uniform coverage of FAs over the whole cell membrane. Longer POEGMA graft-FN conjugates, which are more capable of being laterally deformed, favored the formation of FA complexes toward the periphery of the cells, presumably along their spreading directions. ${ }^{[82]}$ Similar behavior was already observed by Klok et al. for POEGMA-RGD brushes with different OEG side-chain lengths. ${ }^{[83]}$ In this study brush-RGD layers presenting short side chains, i.e., poly(2-hydroxyethyl methacrylate) (PHEMA), induced FA formation in endothelial cells (HUVECs) primarily at the periphery of the cell membranes. Conversely, HUVECs adhering on brushes with longer OEG side chains (6 and 10 OEGs units) showed FAs concentrated toward the cell nuclei. This phenomenon was ascribed to the higher "flexibility" of brush-ligand conjugates presenting shorter side chains (as for PHEMA) compared to the more rigid, sterically hindered POEGMAs.

In addition to FA distribution, the morphological changes by focal contacts across POEGMA-FN gradients indicated that stronger cell attachment was favored on thinner brushes when compared to thicker ones. ${ }^{[50]}$ Higher deformability and frictional dissipation on thicker POEGMA brush-FN conjugates, as measured by FFM, was evidenced by the presence of smaller and less oriented FAs displayed by hMSCs, which also showed decreased spreading. All these indications thus suggested a weaker cell binding on thick POEGMA-FN brushes. In contrast, stronger hMSC attachment on thinner (and less deformable) POEGMA-FN adducts was accompanied by greater cell spreading and diffuse formation of elongated FAs. A similar morphological change was observed by Pelham et al., ${ }^{[49]}$ who showed that elongated FA complexes were formed on rigid substrates, while on compliant supports FAs preferentially adopted dot-like morphologies.

The influence of mechanical energy dissipation by viscoelastic supports on stem-cell spreading and FA formation was recently addressed by Cameron et al. and Chaudhuri et al. ${ }^{[53,54]}$ In both these studies, stem cells adhering on hydrogels characterized by high loss modulus and mechanical stress relaxation displayed enhanced spreading areas compared to elastic substrates with a comparable compressive modulus. In addition, stem cells on viscoelastic materials formed smaller and more transient FAs, inferring an increase of cell mobility and active spreading. The decrease of cell-projected areas showed by hMSCs along the POEGMA brush-thickness gradient seems in contradiction with these previous studies. Nevertheless, we also observed a decrease of FA formation with the increase of brush lateral deformability and frictional dissipation, ascribing it to a weaker cell attachment on thicker and more laterally deformable grafts. Thus, we believe that the impact of bulk viscoelasticity by the support on cell dynamics could certainly be more pronounced than a variation of the interfacial friction, although we demonstrated that also surface properties turned significant.

\section{Conclusion}

Functional polymer brushes supporting FN cues and presenting a gradual variation of brush thickness are effective supports to modulate the physical presentation of the adhesive sites of the ECM where cell attachment takes place. This was demonstrated by applying FFM, which allowed the determination of brush lateral strain and friction as a function of film thickness (grafted-chain length). Brush lateral strain could be measured by analyzing friction loops from FFM. Friction loops displaying a tilted profile before steady sliding were used to evaluate the lateral deformation of swollen brushes and demonstrated that brush lateral strain progressively increased with brush thickness. The analysis of friction-versus-load profiles also confirmed the higher lateral deformability of thicker brushes compared to thinner grafts, while generally, friction, which is directly related to mechanical energy dissipation, steadily increased with brush thickness along the gradient.

POEGMA-FN brush-thickness gradients thus effectively functioned as cell-adhesive ECMs featuring a spatially continuous modulation of lateral deformability of FN cue tethers. This translated into a gradual decrease of cell spreading with increasing tether length (brush thickness) across the gradient, accompanied by the formation of smaller and more peripheral focal contacts by adhered hMSCs. These observations confirmed that the strength of stem cell attachment correlated with the lateral deformability of FN-brush platforms, which could in turn be easily tuned by varying grafted-chain length, i.e., brush thickness (Scheme 2).

The influence of different ligand binding via "designer" macromolecular anchors could thus independently regulate the intracellular mechanisms involved during mechanotransduction. Therefore, one could engineer scaffolds with nearly constant compositions but locally presenting different polymeric grafts constituting a dynamic and synthetic counterpart of the native ECM interface, which could ultimately trigger a precise differentiation pathway when cells are seeded. We have recently proved the feasibility of such a fabrication approach by using PCL-based microporous 3D scaffolds and subsequently functionalizing their exposed interfaces with POEGMA brush coatings. ${ }^{[84]}$ Here, we have further complemented our understanding of cell-substrate interactions by introducing FFM analysis to dissect the role lateral deformability of cell cues and frictional forces at ECM on stem-cell adhesion.

\section{Experimental Section}

Materials: Oligo(ethylene glycol) methacrylate (OEGMA, Aldrich, $M_{\mathrm{n}}=526 \mathrm{~g} \mathrm{~mol}^{-1}$ corresponding to $10 / 11$ OEG units for each monomer) was freed from hydroquinone inhibitors by passing it through a basic alumina column using dichloromethane (DCM, Biosolve) as an eluent. Afterward, DCM was removed under vacuum. Copper $(\mathrm{I})$ chloride $(\mathrm{CuCl}$, Aldrich, 98\%) was purified by stirring in glacial acetic acid, filtering, and washing with ethanol three times, followed by drying in vacuum at room temperature overnight. Poly( $\varepsilon$-caprolactone) $\left(\mathrm{PCL}, M_{\mathrm{n}}=\right.$ $45 \mathrm{kDa}$ ) was obtained from Sigma. Copper(II) bromide (Sigma-Aldrich, $\geq 99 \%$ ), methanol (Biosolve, absolute), isopropanol (iPA, Biosolve), ethylenediamine (EDA, Sigma-Aldrich, $\geq 99 \%$ ), dry hexane (Acros, Extra Dry over Molecular Sieve, 97\%), N,N-dimethylformamide (DMF, Acros, Extra Dry over Molecular Sieve, 99,8\%), pyridine (Sigma-Aldrich, 


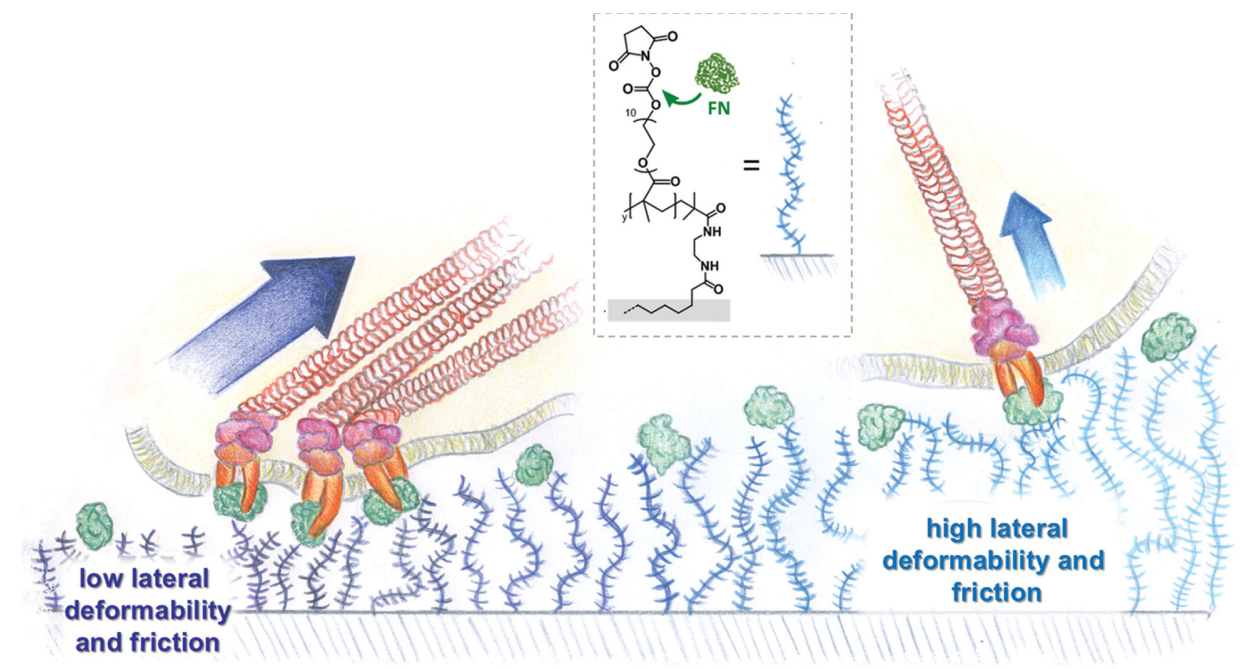

Scheme 2. Schematic representation of hMSCs adhering on FN-POEGMA brush on PCL substrates presenting a gradient of tethered-chain length.

anhydrous, 99,8\%), 2,2'bipyridyl (BiPy, Sigma-Aldrich, $\geq 99 \%$ ), 2-bromoisobutyryl bromide (BIBB, Aldrich, 98\%), 1-bromocarbonyl-1methylethyl acetate (BMA), ethylenediamine tetraacetic acid disodium salt dihydrate (EDTA, Sigma, 99\%), 4-dimethylaminopyridine (DMAP, Sigma-Aldrich, $\geq 99 \%$ ), $N, N^{\prime}$-disuccinimidyl carbonate (DSC, SigmaAldrich, 98\%), triethylamine (Sigma-Aldrich, $\geq 99 \%$ ), and fibronectin (Invitrogen) were used as received. All water used in the experiments was Millipore Milli-Q grade. Human mesenchymal stem cells (hMSCs) were used for the cell culture and were obtained from Donor 249. Basic cell-culture medium was prepared by adding $10 \% \mathrm{v} / \mathrm{v}$ of Fetal Bovine Serum (FBS), $2 \times 10^{-3} \mathrm{M}$ of L-glutamine, $100 \mathrm{U} \mathrm{mL}^{-1}$ of penicillin, $100 \mu \mathrm{g} \mathrm{mL}^{-1}$ of streptomycin, and $0.2 \times 10^{-3} \mathrm{M}$ of ascorbic acid to $\alpha$-MEM cell medium (all components from Invitrogen). Phosphate-buffered saline (PBS), bovine serum albumin (BSA), trypsin, 4',6-diamidino-2phenylindole (DAPI), and rhodamine phalloidin were obtained from Invitrogen. Monoclonal Anti-Vinculin-FITC antibody was purchased from Sigma-Aldrich.

Activation of the Polymer Films: PCL films were spin coated $2000 \mathrm{rpm}$ for $1 \mathrm{~min}$ ) onto cleaned silicon substrates from a chloroform solution (1 wt\%). The spin-coated PCL films were subsequently immersed into a solution of $5 \times 10^{-3} \mathrm{M}$ ethylenediamine (EDA) in isopropanol (iPA). Aminolysis was allowed to proceed on the PCL surface for 10 min under room-temperature conditions. Samples were rinsed with ice water and subsequently rinsed with water at room temperature, then dried in a stream of nitrogen. The aminated PCL films were immersed into $10 \mathrm{~mL}$ of dry hexane and $100 \mu \mathrm{L}$ of dry pyridine, to which 2-bromoisobutyryl bromide (BIBB), and 1-bromocarbonyl-1-methylethyl acetate (BMA) were added dropwise in a predetermined ratio. The reaction mixture was gently stirred for $1 \mathrm{~h}$ at room temperature to produce the 2-bromoisobutyryl-immobilized PCL surface (the PCL-Br surface). The $\mathrm{PCL}-\mathrm{Br}$ substrate was then washed repeatedly with a methanol/water $(1 / 1, v / v)$ mixture and dried under a stream of nitrogen.

Atom Transfer Radical Polymerization of OEGMA: Purified OEGMA monomer (5 g, $9.5 \mathrm{mmol}$ ) and 2,2'bipyridine $(81.7 \mathrm{mg}, 0.52 \mathrm{mmol}$ ) were added to a water $(5 \mathrm{~mL})$ and methanol $(1.26 \mathrm{~mL})$ mixture. The solution was purged with nitrogen for $30 \mathrm{~min}$. $\mathrm{CuCl}(18.75 \mathrm{mg}, 0.19 \mathrm{mmol})$ and $\mathrm{CuBr}_{2}(2 \mathrm{mg}, 0.009 \mathrm{mmol}$ ) were added to another reaction flask and also flushed with nitrogen. Monomer, ligand, and catalyst were then combined and stirred for another 30 min to facilitate the formation of the organometallic complex. This solution was then transferred into the flasks containing the activated PCL substrates. The flasks were sealed with rubber septa and kept at room temperature under nitrogen. After reaching the desired reaction time of $60 \mathrm{~min}$, the substrates were removed from the polymerization solution, exhaustively rinsed with water to remove any unreacted and nonsurface-tethered substances and subsequently dried in a stream of nitrogen. Afterward, the samples were washed with a 0.1 m EDTA solution overnight to extract the copper from the polymer brushes.

Functionalization of OEGMA Brushes with Fibronectin (FN): The succinimidyl carbonate derivative of hydroxyl-terminated side OEG chains on POEGMA brushes was obtained by incubation of the brushfunctionalized $\mathrm{PCL}$ substrates in a dry DMF solution containing $0.2 \times 10^{-3} \mathrm{M}$ of DSC and DMAP. Subsequently the samples were incubated in a PBS $0.1 \times 10^{-3} \mathrm{M} F N$ solution overnight in order to covalently couple the $\mathrm{FN}$ to the polymer brush.

Ellipsometry: Thickness measurements of polymer brushes were performed using a variable-angle spectroscopic ellipsometer (VASE) (J. A. Woollam Co., Lincoln, NE, USA) in the range from 1 to $4.5 \mathrm{eV}$ with a step size of $0.1 \mathrm{eV}$; this corresponds to a wavelength range of 275-1240 nm. The measurements were carried out at three different incident angles, namely $65^{\circ}, 70^{\circ}$, and $75^{\circ}$. Measurements in ultrapure water and cell culture medium were conducted in a liquid cell containing two windows at a fixed angle of incidence of $\theta=63^{\circ}$. A third window enabled alignment of the sample at normal incidence as well as allowed visual inspection of the sample during in situ experiments. The dry thickness of the gradient samples was measured at equidistant positions $(5 \mathrm{~mm})$ along the sample. The ellipsometry spectra, i.e., $\Psi$ and $\Delta$ as a function of wavelength, were analyzed using the CompleteEASE software package (Woollam), employing the tabulated dielectric functions for both silicon and silicon oxide as the substrate. A standard Cauchy model was employed to analyze the thickness of the spin-coated PCL, and the total thickness of the collapsed POEGMA brush layer and PCL. Subtracting the PCL layer thickness before polymerization, from the total thickness after polymerization yielded the POEGMA thickness. The swollen thickness of POEGMA brushes both immersed in ultrapure water and in $\alpha$-MEM medium was also measured. Modeling of the optical parameters in these media was accomplished using a graded Cauchy model for the POEGMA swollen layer on top of a fitted PCL layer, as previously reported. ${ }^{[85,86]}$

The grafting density $(\sigma),{ }^{[87]}$ was calculated according to Equation (1)

$\sigma=\rho_{0} h_{\text {dry }} \mathrm{N}_{\mathrm{A}}\left(\mathrm{NM}_{0}\right)^{-1}$

where $\rho_{0}$ is the estimated POEGMA layer density $\left(1.40 \mathrm{~g} \mathrm{~cm}^{-3}\right), N_{\mathrm{A}}$ is the Avogadro's number, $M_{0}$ is the monomer molecular weight $(526 \mathrm{~g}$ $\mathrm{mol}^{-1}$ ), and $N$ is the degree of polymerization, which was estimated according to Equation (2)

$N=[0.227]\left(h_{\text {swollen }}\right)^{3 / 2}\left(h_{\text {dry }}\right)^{-1 / 2}$ 
where $h_{\text {swollen }}$ and $h_{\mathrm{dry}}$ are the brush thicknesses measured in ultrapure water and in dry conditions by VASE, respectively, while 0.227 is a constant related to the excluded volume parameter and the Kuhn length of a monomer unit.

X-Ray Photoelectron Spectroscopy (XPS): A Quantera SXM scanning XPS microprobe (Physical Electronics, Chanhassen, MN, USA) using an $\mathrm{Al} \mathrm{K} \alpha$, monochromatic $\mathrm{X}$-ray at $1486.6 \mathrm{eV}$ was used to measure the atomic composition of the surfaces of POEGMA brushes with or without $\mathrm{FN}$ functionalization. The surface coverage of $\mathrm{FN}\left(\sigma_{\mathrm{FN}}\right)$ was calculated using Equation (3):

$$
\sigma_{\mathrm{FN}}=\rho \mathrm{hr}_{\mathrm{N} / \mathrm{C}, \text { sample }}\left(\mathrm{r}_{\mathrm{N} / \mathrm{C}, \mathrm{FN}}\right)^{-1}
$$

where $\rho$ is the density $\left(1 \mathrm{~g} \mathrm{~cm}^{-3}\right), h$ is the sampling depth of XPS $(7.5 \mathrm{~nm}),{ }^{[88]}$ and $r$ is the nitrogen to carbon ratio measured for POEGMA-FN conjugates and for pure FN (0.270). ${ }^{[89]}$

Cell Culture and Cell Imaging: Human mesenchymal stem cells were cultured at $37{ }^{\circ} \mathrm{C}$ in a humidified atmosphere containing $5 \%$ carbon dioxide, using $\alpha$-MEM supplemented with $10 \% \mathrm{v} / \mathrm{v} \mathrm{FBS,} 2 \times 10^{-3} \mathrm{M}$ L-glutamine, $1 \times 10^{-3} \mathrm{M}$ sodium pyruvate, $100 \mathrm{U} \mathrm{mL}^{-1}$ of penicillin and $100 \mu \mathrm{g} \mathrm{mL}^{-1}$ of streptomycin as a culture medium. The cells were seeded at a density of 2000 cells $\mathrm{cm}^{-2}$ on PCL substrates, unmodified and modified with POEGMA brushes. After $4 \mathrm{~h}$, the substrates were washed twice with PBS and fixed with a $3.7 \% \mathrm{v} / \mathrm{v}$ formaldehyde solution in PBS for $10 \mathrm{~min}$ at room temperature. Next, the samples were washed two or more times with PBS containing $1 \% \mathrm{w} / \mathrm{v}$ bovine-serum albumin (BSA). The cell membranes were permeabilized by treating the samples with $0.1 \% \mathrm{v} / \mathrm{v}$ Triton X-100 solution in PBS-BSA, after which the specimens were washed again with PBS-BSA. The FA points were stained overnight at $0{ }^{\circ} \mathrm{C}$ using a monoclonal Anti-Vinculin-Fluorescein isothiocyanate (FITC) antibody, and diluted 1:400 in a PBS-BSA solution. Cell nuclei were stained with 4',6-diamidino-2-phenylindole (DAPI) diluted 1:100 and the cell cytoskeleton was stained with a rhodamine phalloidin diluted 1:50 in a PBS-BSA solution for $30 \mathrm{~min}$ at room temperature. Images were taken using an Eclipse E600 fluorescence microscope (Nikon, Tokyo, Japan). In order to prepare the samples for optical imaging, they were dehydrated by immersion into an ascending concentration series of aqueous ethanol solutions each for $10 \mathrm{~min}$. Optical imaging was performed on a BX60 optical microscope (Olympus, Tokyo, Japan). For determining the cell-shape parameters, Cell^D software (Olympus Soft Imaging Solutions, Münster, Germany) was used.

The FA area and aspect-ratio shape parameters were determined using Image) software version $1.47 \mathrm{v}$ (National Institutes of Health, USA). To test the statistical significance of the difference in the cell shape parameters, a one-way ANOVA test followed by a Tukey's post hoc test was performed. Statistical significance was set at a $p$ value of 0.05 .

Atomic Force Microscopy: Normal and lateral force measurements between a silica microsphere and POEGMA-FN brush films were carried out in $\alpha$-MEM medium using an AFM (MFP3D, Asylum Research, Santa Barbara, USA) equipped with a liquid cell. The normal spring constant of the Au-coated, tipless cantilever (NSC-12, Mikromash, Estonia) was measured by the thermal-noise method. ${ }^{[90]}$ Friction measurements were carried out applying normal loads within the range $0-300 \mathrm{nN}$ and by scanning the cantilever laterally across the brush gradient surface. The recorded scanning distance corresponds to the piezo displacement by the AFM scanner supporting the sample during a FFM measurement. The torsional spring $\left(K_{\mathrm{T}}\right)$ constant of the cantilevers used for LFM was measured by Sader's method, ${ }^{[91]}$ using the online calibration applet (http://www.ampc.ms.unimelb.edu.au/afm/calibration.html). The lateral sensitivity $\left(S_{L}\right)$ of the cantilever was obtained using the test-probe method, as described by Cannara et al. ${ }^{[92]}$ Briefly, a silicon wafer was cut along its 100 crystal plane and glued to a glass slide such that the smooth edge of the silicon wafer was used as a vertical wall to twist the cantilever laterally. The lateral sensitivity of the cantilever bearing a $35 \mu \mathrm{m}$ of diameter colloid (larger than the width of the cantilever) was obtained by recording the lateral deflection-versus-piezo displacement curve and fitting the approaching profile with a linear regression. The slope of this latter line provided the lateral sensitivity value. The torsional spring constant was converted to the lateral spring constant $\left(K_{\mathrm{L}}\right)$ by means of the relation $K_{\mathrm{L}}=K_{\mathrm{T}} h^{-2}$, where $h$ is the torsional arm length (equal to the sum of the diameter of the sphere and half the thickness of the cantilever beam).

The measured lateral signal (provided in Volts from the photodetector) was converted to lateral force by applying a conversion factor $(\alpha)$ defined as $\alpha=K_{\mathrm{L}} / S_{\mathrm{L}}$.

A silica microparticle of radius $8 \mu \mathrm{m}$ (EKA chemicals $A B$, Kromasil R) was glued with UV-curable adhesive (Norland optical adhesive) to the end of the tipless cantilever by means of a home-built micromanipulator, to be further used for colloidal probe microscopy. ${ }^{[3]}$

\section{Supporting Information}

Supporting Information is available from the Wiley Online Library or from the author.

\section{Acknowledgements}

This work was financially supported by the Swiss National Science Foundation (SNSF "Ambizione" PZ00P2-148156), the MESA+ Institute for Nanotechnology of the University of Twente and by the Technology foundation STW (STW, 11135). The authors thank Prof. Nicholas D. Spencer (ETH Zürich) and Prof. Nancy Burnham (Worchester Polytechnic) for the many useful discussions.

Received: August 18, 2015

Revised: October 29, 2015

Published online: December 11, 2015

[1] R. Barbey, L. Lavanant, D. Paripovic, N. Schuwer, C. Sugnaux, S. Tugulu, H. A. Klok, Chem. Rev. 2009, 109, 5437.

[2] S. Edmondson, V. L. Osborne, W. T. S. Huck, Chem. Soc. Rev. 2004, $33,14$.

[3] L. Andruzzi, W. Senaratne, A. Hexemer, E. D. Sheets, B. Ilic, E. J. Kramer, B. Baird, C. K. Ober, Langmuir 2005, 21, 2495.

[4] L. Moroni, M. Klein Gunnewiek, E. M. Benetti, Acta Biomater. 2014, 10, 2367.

[5] R. C. Advincula, W. J. Brittain, K. C. Caster, J. Ruhe, Polymer Brushes: Synthesis, Characterization, Applications, Wiley-VCH, Weinheim, Germany 2004

[6] R. Barbey, E. Kauffmann, M. Ehrat, H. A. Klok, Biomacromolecules 2010, 11, 3467.

[7] D. Paripovic, H. Hall-Bozic, H. A. Klok, J. Mater. Chem. 2012, 22, 19570.

[8] J. E. Gautrot, W. T. S. Huck, M. Welch, M. Ramstedt, ACS Appl. Mater. Interfaces 2010, 2, 193.

[9] Z. L. Zhou, P. P. Yu, H. M. Geller, C. K. Ober, Biomacromolecules 2013, 14, 529.

[10] T. Gillich, E. M. Benetti, E. Rakhmatullina, R. Konradi, W. Li, A. Zhang, A. D. Schluter, M. Textor, J. Am. Chem. Soc. 2011, 133, 10940.

[11] E. M. Benetti, X. F. Sui, S. Zapotoczny, G. J. Vancso, Adv. Funct. Mater. 2010, 20, 939.

[12] A. Li, E. M. Benetti, D. Tranchida, J. N. Clasohm, H. Schonherr, N. D. Spencer, Macromolecules 2011, 44, 5344.

[13] K. Y. Tan, H. Lin, M. Ramstedt, F. M. Watt, W. T. S Huck, J. E. Gautrot, Integr. Biol. 2013, 5, 899.

[14] A. Kovalev, H. Shulha, M. Lemieux, N. Myshkin, V. V. Tsukruk, J. Mater. Res. 2004, 19, 716. 
[15] C. M. Mate, G. M. Mcclelland, R. Erlandsson, S. Chiang, Phys. Rev. Lett. 1987, 59, 1942.

[16] U. Raviv, S. Giasson, N. Kampf, J. F. Gohy, R. Jerome, J. Klein, Nature 2003, 425, 163.

[17] M. T. Muller, X. P. Yan, S. W. Lee, S. S. Perry, N. D. Spencer, Macromolecules 2005, 38, 5706.

[18] S. Lee, N. D. Spencer, Science 2008, 319, 575.

[19] Z. Y. Zhang, A. J. Morse, S. P. Armes, A. L. Lewis, M. Geoghegan, G. J. Leggett, Langmuir 2013, 29, 10684.

[20] M. Raftari, Z. Y. Zhang, S. R. Carter, G. J. Leggett, M. Geoghegan, Soft Matter 2014, 10, 2759.

[21] M. Kobayashi, Y. Terayama, M. Kikuchi, A. Takahara, Soft Matter 2013, 9, 5138.

[22] F. M. Watt, B. L. M. Hogan, Science 2000, 287, 1427.

[23] D. T. Scadden, Nature 2006, 441, 1075.

[24] C. M. Metallo, J. C. Mohr, C. J. Detzel, J. J. de Pablo, B. J. Van Wie, S. P. Palecek, Biotechnol. Progr. 2007, 23, 18.

[25] J. Elisseeff, A. Ferran, S. Hwang, S. Varghese, Z. Zhang, Stem Cells Dev. 2006, 15, 295.

[26] S. M. Dellatore, A. S. Garcia, W. M. Miller, Curr. Opin. Biotech. 2008, 19, 534.

[27] S. Battista, D. Guarnieri, C. Borselli, S. Zeppetelli, A. Borzacchiello, L. Mayol, D. Gerbasio, D. R. Keene, L. Ambrosio, P. A. Netti, Biomaterials 2005, 26, 6194.

[28] F. Guilak, D. M. Cohen, B. T. Estes, J. M. Gimble, W. Liedtke, C. S. Chen, Cell Stem Cell 2009, 5, 17.

[29] H. A. Awad, M. Q. Wickham, H. A. Leddy, J. M. Gimble, F. Guilak, Biomaterials 2004, 25, 3211.

[30] B. Johnstone, T. M. Hering, A. I. Caplan, V. M. Goldberg, J. U. Yoo, Exp. Cell Res. 1998, 238, 265.

[31] A. J. Engler, S. Sen, H. L. Sweeney, D. E. Discher, Cell 2006, 126, 677.

[32] P. Bianco, P. G. Robey, P. J. Simmons, Cell Stem Cell 2008, 2, 313.

[33] R. Ayala, C. Zhang, D. Yang, Y. Hwang, A. Aung, S. S. Shroff, F. T. Arce, R. Lal, G. Arya, S. Varghese, Biomaterials 2011, 32, 3700.

[34] R. J. McMurray, N. Gadegaard, P. M. Tsimbouri, K. V. Burgess, L. E. McNamara, R. Tare, K. Murawski, E. Kingham, R. O. C. Oreffo, M. J. Dalby, Nat. Mater. 2011, 10, 637.

[35] J. P. Winer, P. A. Janmey, M. E. McCormick, M. Funaki, Tissue Eng. Pt. A 2009, 15, 147.

[36] K. Saha, A. J. Keung, E. F. Irwin, Y. Li, L. Little, D. V. Schaffer, K. E. Healy, Biophys. J. 2008, 95, 4426.

[37] X. Hu, S. H. Park, E. S. Gil, X. X. Xia, A. S. Weiss, D. L. Kaplan, Biomaterials 2011, 32, 8979.

[38] J. S. Choi, B. A. C. Harley, Biomaterials 2012, 33, 4460.

[39] N. D. Leipzig, M. S. Shoichet, Biomaterials 2009, 30, 6867.

[40] B. Trappmann, J. E. Gautrot, J. T. Connelly, D. G. T. Strange, Y. Li, M. L. Oyen, M. A. C. Stuart, H. Boehm, B. J. Li, V. Vogel, J. P. Spatz, F. M. Watt, W. T. S. Huck, Nat. Mater. 2012, 11, 642.

[41] N. Huebsch, P. R. Arany, A. S. Mao, D. Shvartsman, O. A. Ali, S. A. Bencherif, J. Rivera-Feliciano, D. J. Mooney, Nat. Mater. 2010, 9, 518.

[42] J. S. Park, J. S. Chu, A. D. Tsou, R. Diop, Z. Y. Tang, A. J. Wang, S. Li, Biomaterials 2011, 32, 3921.

[43] D. E. Discher, P. Janmey, Y. L. Wang, Science 2005, 310, 1139.

[44] G. M. Harris, M. E. Piroli, E. Jabbarzadeh, Adv. Funct. Mater. 2014, 24, 2396

[45] J. P. Fu, Y. K. Wang, M. T. Yang, R. A. Desai, X. A. Yu, Z. J. Liu, C. S. Chen, Nat. Methods 2010, 7, 733.

[46] D. Choquet, D. P. Felsenfeld, M. P. Sheetz, Cell 1997, 88, 39.

[47] S. Khetan, M. Guvendiren, W. R. Legant, D. M. Cohen, C. S. Chen, J. A. Burdick, Nat. Mater. 2013, 12, 458.

[48] J. H. Wen, L. G. Vincent, A. Fuhrmann, Y. S. Choi, K. C. Hribar, H. Taylor-Weiner, S. C. Chen, A. J. Engler, Nat. Mater. 2014, 13, 979.
[49] R. J. Pelham, Y. L. Wang, P. Natl. Acad. Sci. USA, 1997, 94, 13661.

[50] N. Q. Balaban, U. S. Schwarz, D. Riveline, P. Goichberg, G. Tzur, I. Sabanay, D. Mahalu, S. Safran, A. Bershadsky, L. Addadi, B. Geiger, Nat. Cell Biol. 2001, 3, 466.

[51] D. Riveline, E. Zamir, N. Q. Balaban, U. S. Schwarz, T. Ishizaki, S. Narumiya, Z. Kam, B. Geiger, A. D. Bershadsky, J. Cell Biol. 2001, 153, 1175.

[52] G. Giannone, B. J. Dubin-Thaler, O. Rossier, Y. F. Cai, O. Chaga, G. Y. Jiang, W. Beaver, H. G. Dobereiner, Y. Freund, G. Borisy, M. P. Sheetz, Cell 2007, 128, 561.

[53] A. R. Cameron, J. E. Frith, J. J. Cooper-White, Biomaterials 2011, 32, 5979.

[54] O. Chaudhuri, L. Gu, M. Darnell, D. Klumpers, S. A. Bencherif, J. C. Weaver, N. Huebsch, D. J. Mooney, Nat. Commun. 2015, 6.

[55] A. S. Smith, K. Sengupta, S. Goennenwein, U. Seifert, E. Sackmann, Proc. Natl. Acad. Sci. USA 2008, 105, 6906.

[56] T. Pompe, T. Bischoff, S. Glorius, S. Johne, M. Kasimir, M. Kaufmann, I. Uhlmann, M. Bobeth, W. Pompe, C. Werner, Biophys. J. 2011, 100, 598.

[57] T. Pompe, M. Kaufmann, M. Kasimir, S. Johne, S. Glorius, L. Renner, M. Bobeth, W. Pompe, C. Werner, Biophys. J. 2011, 101, 1863.

[58] T. E. Angelini, A. C. Dunn, J. M. Uruena, D. J. Dickrell, D. L. Burris, W. G. Sawyer, Faraday Discuss. 2012, 156, 31.

[59] C. Muller, D. R. Stamov, C. Werner, T. Pompe, Ultramicroscopy 2012 , 118, 44.

[60] C. Muller, A. Muller, T. Pompe, Soft Matter 2013, 9, 6207.

[61] K. Matyjaszewski, P. J. Miller, N. Shukla, B. Immaraporn, A. Gelman, B. B. Luokala, T. M. Siclovan, G. Kickelbick, T. Vallant, H. Hoffmann, T. Pakula, Macromolecules 1999, 32, 8716.

[62] T. E. Patten, K. Matyjaszewski, Adv. Mater. 1998, 10, 901.

[63] K. Matyjaszewski, N. V. Tsarevsky, Nat. Chem. 2009, 1, 276.

[64] N. Singh, X. F. Cui, T. Boland, S. M. Husson, Biomaterials 2007, 28, 763.

[65] H. W. Ma, J. H. Hyun, P. Stiller, A. Chilkoti, Adv. Mater. 2004, 16, 338.

[66] A. A. Brown, N. S. Khan, L. Steinbock, W. T. S. Huck, Eur. Polym. J. 2005, 41, 1757.

[67] M. Lemieux, D. Usov, S. Minko, M. Stamm, H. Shulha, V. V. Tsukruk, Macromolecules 2003, 36, 7244.

[68] D. Goodman, J. N. Kizhakkedathu, D. E. Brooks, Langmuir 2004, 20, 2333.

[69] A. Li, S. N. Ramakrishna, P. C. Nalam, E. M. Benetti, N. D. Spencer, Adv. Mater. Interf. 2014, 1, 1300007.

[70] It is worth mentioning that within the range of scanning rates included between 20 and $400 \mathrm{~nm} \mathrm{sec}$, no differences in the tilted section of the friction force loops were recorded, as reported in Figure S7 in the Supporting Information.

[71] L. Miao, H. Guo, M. J. Zuckermann, Macromolecules 1996, 29, 2289.

[72] Y. Rabin, S. Alexander, Europhys. Lett. 1990, 13, 49.

[73] P. S. Doyle, E. S. G. Shaqfeh, A. P. Gast, Phys. Rev. Lett. 1997, 78, 1182.

[74] P. S. Doyle, E. S. G. Shaqfeh, A. P. Gast, Macromolecules 1998, 31, 5474.

[75] Y. W. Kim, V. Lobaskin, C. Gutsche, F. Kremer, P. Pincus, R. R. Netz, Macromolecules 2009, 42, 3650.

[76] R. W. Carpick, D. F. Ogletree, M Salmeron, J. Colloid Interf. Sci. 1999, 211, 395.

[77] K. L. Johnson, K. Kendall, A. D. Roberts, Proc. R. Soc. Lon. Ser. A 1971, 324, 301.

[78] B. V. Derjaguin, V. M. Muller, Y. P. Toporov, J. Colloid Interface Sci. 1975, 53, 314.

[79] G. Amontons, Hist. Acad. R. Sci. 1699, 206.

[80] R. J. Pelham, Y. L. Wang, Biol. Bull. 1998, 194, 348. 
[81] R. Zaidel-Bar, M. Cohen, L. Addadi, B. Geiger, Biochem. Soc. Trans. 2004, 32, 416.

[82] A. P. Kourouklis, R. V. Lerum, H. Bermudez, Biomaterials 2014, 35, 4827.

[83] S. Tugulu, P. Silacci, N. Stergiopulos, H. A. Klok, Biomaterials 2007, 28, 2536.

[84] M. Klein Gunnewiek, A. Di Luca, H. Z. Bollemaat, C. A. van Blitterswijk, G. J. Vancso, L. Moroni, E. M. Benetti, Adv. Health. Mater. 2015, 4, 1169.

[85] M. Klein Gunnewiek, E. M. Benetti, A. Di Luca, C. A. van Blitterswijk, L. Moroni, G. J. Vancso, Langmuir 2013, 29, 13843.

[86] Q. Chen, E. S. Kooij, X. F. Sui, C. J. Padberg, M. A. Hempenius, P. M. Schon, G. J. Vancso, Soft Matter 2014, 10, 3134.
[87] R. Jordan, A. Ulman, J. F. Kang, M. H. Rafailovich, J. Sokolov, J. Am. Chem. Soc. 1999, 121, 1016.

[88] K. L. Tan, L. L. Woon, H. K. Wong, E. T. Kang, K. G. Neoh, Macromolecules 1993, 26, 2832.

[89] A. Galtayries, R. Warocquier-Clérout, M. D. Nagel, P. Marcus, Surf. Interface Anal. 2006, 38, 186.

[90] H. J. Butt, M. Jaschke, Nanotechnology 1995, 6, 1.

[91] C. P. Green, H. Lioe, J. P. Cleveland, R. Proksch, P. Mulvaney, J. E. Sader, Rev. Sci. Instrum. 2004, 75, 1988.

[92] R. J. Cannara, M. Eglin, R. W. Carpick, Rev. Sci. Instrum. 2006, 77, 053701.

[93] W. A. Ducker, T. J. Senden, R. M. Pashley, Nature 1991, 353, 239. 